This is the author's final, peer-reviewed manuscript as accepted for publication. The publisher-formatted version may be available through the publisher's web site or your institution's library.

\title{
Relationship quality among young couples from an economic and gender perspective
}

Sonya L. Britt, R. Roudi Nazarinia Roy

\section{How to cite this manuscript}

If you make reference to this version of the manuscript, use the following information:

Britt, S. L., \& Nazarinia Roy, R. R. (2014). Relationship quality among young couples from an economic and gender perspective. Retrieved from http://krex.ksu.edu

\section{Published Version Information}

Citation: Britt, S. L., \& Nazarinia Roy, R. R. (2014). Relationship quality among young couples from an economic and gender perspective. Journal of Family and Economic Issues, 35(2), 241-250.

Copyright: @ Springer Science+Business Media New York 2013

Digital Object Identifier (DOI): doi:10.1007/s10834-013-9368-x

Publisher's Link: http://link.springer.com/article/10.1007/s10834-013-9368-x

This item was retrieved from the K-State Research Exchange (K-REx), the institutional repository of Kansas State University. K-REx is available at http://krex.ksu.edu 


\title{
Relationship Quality among Young Couples from an Economic and Gender Perspective
}

\begin{abstract}
Less than a third of married couple households in the United States are composed of families with one breadwinner. This is a stark contrast to a mere 40 years ago when men were the primary breadwinner for the majority of households. The goal of this study was to determine how the perception of household chores is related to relationship quality. Specifically we wanted to determine how perception of household chores is related to relationship quality reported by partners from a traditional economic and a gender role theory perspective. Using data from the National Longitudinal Survey of Youth, 1986 cohort, results indicate that perceived unfair in household division of chores was predictive of women's relationship quality, but not men's. Arguments about affection and money were predictive of relationship quality for both genders.
\end{abstract}




\section{Introduction}

With women's growing presence in the paid work force, traditional marital trends are changing. As opposed to 40 years ago, men are no longer automatically seen as the breadwinner of the family and women as the homemaker. Not only are dual earner couples in the majority, there has also been a shift in the traditional gender roles of breadwinner and homemaker. This is evident in the fact that less than $30 \%$ of married couple households in the United States are composed of families with one breadwinner; less than $22 \%$ of these families have a traditional male-breadwinner and female-homemaker household leaving over $7 \%$ of households to report the female as the main breadwinner (U.S. Census Bureau 2011). With an increase in the labor force participation by women one would suspect greater household labor participation by men. Although an egalitarian division of housework is reported to be an ideal division among young unmarried women, these women do not expect as much equality in their future relationships as their male counterparts (Askari et al. 2010). The primary purpose of this study is to determine how the perception of household chores is related to relationship quality reported by partners.

Older studies conducted in the 1990s show that unfair perceptions of household chore allocation are associated with decreased relationship quality (Blair and Johnson 1992; Greenstein 2000). Recent research indicates that household chore decisions are more related to traditional gender role attitudes (Askari et al. 2010; Kroska 2003). Young, unmarried women still perceive that they will engage in more household chores than their heterosexual partner despite both sexes having a preference for more egalitarian relationships (at least in terms of household and child care chores) (Askari et al. 2010).

Partners appear to actively consider the division of household chores in the partner selection process (Askari et al. 2010). Career oriented individuals are likely to try to find a more 
family oriented partner who will care for more of the household chore responsibilities allowing the career oriented partner to spend less time doing household chores. Career oriented individuals who do not anticipate finding a family oriented partner, may anticipate that they will engage in more household chores than they actually desire (Orrange 2002).

The purpose of this study was to determine how the perception of household chores is related to relationship quality among younger couples while simultaneously controlling for other known influences of perceived relationship quality including the commonly written about arguments about money and sex/affection. Younger couples tend to be more egalitarian in their divisions of labor than previous generations making them an interesting target population for this topic (Brewster and Padovic 2000). The research question was approached from a traditional economic theory perspective, which states that the partner with the greatest level of resources makes household decisions largely ignoring sex and culture differences, in addition to a gender theory perspective, which accounts for couples subscribing to traditional gender roles. Because economic factors alone may not explain the variations reposted among couples (Weagley et al. 2007), the application of two theoretical perspectives was meant to increase our ability to explain possible variations reported in couples' relationship quality.

\section{Theoretical Framework and Related Literature}

Economic theory, particularly Becker's (1976) theory of marriage, is well established and has commonly been used to address marital choice and decision making. The basic premise of Becker's theory of marriage is that partners weigh the costs and benefits associated with marriage to determine if they should get married and then stay married. If partners are able to contribute to the overall household utility function in terms of income through paid work or increased household production, couples are happy and relationship quality is high. Partners may 
decide to specialize in market or household work to further maximize household utility.

Decisions regarding resource allocation may result in conflict if partners disagree on how to allocate their limited resources. As couples are together for longer periods of time, they develop relationship specific capital which cannot be transferred to another relationship. This, thereby, increases the costs of relationship dissolution making marriage the more attractive scenario.

One such critique of this and other economic and resource exchange theories is their assumption that rational choice and exchange principles are gender-neutral (Coltrane and Shih 2010). In order to provide a more accurate picture of how the division of household labor relates to relationship satisfaction, it is necessary to also account for gender. Gender theory goes beyond the rational reflection of resource and time demands and accounts for the socially constructed boundaries delineating gender as it relates to the division of paid and domestic work (Ferree 1990; Thompson and Walker 1989). Gender is a social and cultural construct; as such, gender theory would suggest that the gendered division of household labor is due to a process of socialization. Thus, the incorporation of gender theory is essential to any role evaluation that includes both men and women. The following sections discuss the three concepts of resource allocation, assortative mating, and relationship investment from both economic and gender theory perspectives.

\section{Resource Allocation}

Time and money are two of the most commonly referenced resource constraints. Couples must constantly decide how to allocate their time and money to maximize both household and individual utility. An unfair perception of household chore allocation is likely to lead to conflict among partners given that one partner feels they are using their time inefficiently. 
The other two most commonly argued about topics for couples include money and sex (Dew et al. 2012). According to Britt, Huston, and Durband (2010), "Couples with no, or infrequent, money arguments will generally have more resources (e.g., time, energy) to allocate to other activities as opposed to couples who argue about money more frequently" (p. 44). In other words, there is a finite amount of time in each day. If couples spend time arguing, there is less time available for other more satisfying activities, such as talking about their day, playing games, or engaging in other leisurely activities.

\section{Assortative Mating}

Assortative mating refers to the notion of finding a partner that brings either similar (positive assortative mating) or different (negative assortative mating) characteristics to the relationship. In the past, it was more common for husbands to specialize in paid market work and wives to specialize in non-paid household work (i.e., marry based on negative assortative mating). This allowed the household, as a whole, to achieve maximum utility by each partner maximizing skill in one area (Becker 1976). Recent research suggests that this decision should not be as gender-specific as it once was. Rather, individuals should do what they are best at (i.e., the tasks they can do quickest with the least amount of energy) versus what is considered a stereotypical male or female task to maximize the benefits of marriage (Szuchman and Anderson 2011).

Gender Role Attitudes. The adoption of more non-traditional attitudes towards gender however has different consequences for men and women. Women with more non-traditional gender attitudes are likely to have lower subsequent levels of marital satisfaction, whereas men with these non-traditional attitudes experience higher subsequent levels of marital satisfaction (Amato and Booth 1995). This is perhaps due to the fact that men with more non-traditional 
gender attitudes perform a larger portion of domestic work (Amato and Booth 1995). It would not be far reaching to assume that non-traditional gender attitudes are perhaps the reason we see more women employed in higher status positions and more men performing greater household tasks, thus a link between gender role attitudes and women's employment as suggested by Brooks and Bolzendahl (2004).

Work and Income. Since 1970, the employment of women, especially mothers, has risen by well over $20 \%$ with current reports estimating that over $61 \%$ of married women are in the work force (U.S. Census Bureau 2011). Although the number of women in the paid work force has dramatically increased, women continue to perform two to three times more of the household labor than their partners (Coltrane 2000) regardless of their family structure or employment status (Demo and Acock 1993). Although husbands in unconventional marriages do more domestic work than their conventional counterparts, they still do not do more than their wives, nor does an unconventional wife's income give her more control over money or decision making power in her marriage (Tichenor 1999).

Researchers have specifically examined the influence of women's employment on the gendered nature of household tasks (Bittman et al. 2003); women's increased paid labor force participation has not led to greater equality in shared household tasks (Fuwa and Cohen 2007; Lincoln 2008). Although there are only a small portion of families in which a husband and wife share domestic work equally (Gershuny and Sullivan 2003), literature indicates that there has been a great increase in the non-traditional gender attitudes of younger generations of women over the past decades (Brewster and Padovic 2000).

\section{Relationship Investment}


Cohabitation versus marriage. Although on the surface cohabitors and married couples may look the same, sharing a residence and having daily interactions with one another, there are distinct differences between the two. For example, cohabitators tend to be less committed and less happy in their relationships (Nock 1995). In an investigation exploring the factors that attribute to the cohesiveness of cohabiting and married couples, Brines and Joyner (1999) found that the general proxies of joint investment—such as children and duration of relationship do not predict stability in cohabiting relationships in the same way they do marital relationships. This emphasizes the unpredictability in the stability of cohabiting relationships as compared to marriage. They also reported that cohabitors are less likely to break up the more time they both spend in paid work (Brines and Joyner 1999).

Children. Numerous studies have suggested that parenthood is associated with more traditional divisions of household labor (Baxter et al. 2008; Biehle and Mickelson 2012; Cowan and Cowan 2000). In terms of relationship quality, the literature is mixed. Some research suggests that children increases relationship quality (Cowan and Cowan 2000), while some research suggests there is a negative (Lawrence et al. 2008; Shapiro et al. 2000) or curvilinear (Rollins and Feldman 1970) association between children and relationship quality. The negative effects of children on relationships have been found across a wide range of ethnicities, including both Caucasian and African-American couples within the United States (Crohan 1996) and continents such as Asia (Lu 2006) and Europe (Lorensen et al. 2004; Salmela-Aro et al. 2006). Declines in marital quality have also been reported across countries that have varying family policy regulations, women employment patterns and gendered role divisions such as the United States (Shapiro et al. 2000), England (Moss et al. 1986), Germany (Engfer 1988), and the Netherlands (Kluwer and Mikula 2002). It has also been suggested that children have a 
paradoxical effect on relationships such that having children increases marital stability while simultaneously decreases marital quality (Bradbury et al. 2000).

\section{Method}

\section{Data}

Data were obtained from the National Longitudinal Survey of Youth (NLSY) 1986-2010 cohort. The 1986-2010 cohort includes the children (aged 15 or older) of the women originally surveyed in the 1979 NLSY cohort (data collection began in 1979 with 12,686 respondents). The 1986-2010 cohort has been surveyed on a biennial basis since 1986. In 2010, the children were between the ages of 18 and 39 with an average age of 29. The sample was restricted to people in a committed relationship who were either married or living with a significant other. The total sample size after eliminating cases with missing data was 554 .

\section{Measures}

\section{Dependent Variable}

Relationship quality was operationalized by a "perfect" score on the summation of three questions from the NLSY. Respondents were asked to indicate how frequently they had calm discussions and laughed together with their partner. Response options for these two questions included almost every day (1), once or twice a week (2) once or twice a month (3), and less than once a month (4). Respondents were then asked how often they tell their partner about their day where 1 = almost every day, $2=$ once or twice a week, $3=$ once or twice a month, and $4=$ less than once a month. Scores were reverse coded so that higher scores represented more positive interactions with one's partner. The three items were added together for a total possible score of 3 to 12 .

Independent Variables 
Concepts hypothesized to influence relationship quality based on Becker's (1976) theory of marriage include resource allocation (i.e., how limited time, money, and other resources are used), assortative mating (i.e., tendency to be involved with partners with similar or complementary characteristics), relationship investment (i.e., amount of time spent developing the relationship).

Resource Allocation. The independent variable of interest was perceived fairness with chore allocations to proxy perceived time usage between partners within the household. Respondents were asked to indicate which of the following categories most represented the sharing of housework between them and their partner: (a) I do much more than my fair share of the household work, (b) I do a bit more than my fair share of the household work, (c) I do roughly my fair share of the household work, (d) I do a bit less than my fair share of the household work, and (e) I do much less than my fair share of the household work. Respondents were grouped into three categories: those who (a) reported to do roughly their share of household chores capturing category c from above, (b) reported to do more than their fair share capturing categories $\mathrm{a}$ and $\mathrm{b}$ from above, and (c) reported to do less than their fair share capturing categories $\mathrm{d}$ and e from above.

Partners who spend a lot of time arguing reduce the amount of time available for other, more satisfying activities. Arguments about sex and money are two of the most often cited correlates with relationship quality (Dew 2009; Dew et al. 2012), so the frequency of arguments about these topics was used to control for their influence on relationship quality. Each argument variable was measured on a scale of one to four $(1=$ often argue, $2=$ sometimes argue, $3=$ rarely 
argue, and $4=$ never argue). Items were reverse coded so that higher scores represent more frequent arguing ${ }^{1}$.

Assortative Mating. Respondents' income minus their partners' income was calculated to determine differences in income earned. The same formula was used to determine differences in hours worked each week.

The sum of eight items related to traditional gender role attitudes was used $(\alpha=.62)$ including (a) a woman's place is in the home, (b) a wife with a family has no time for other employment, (c) a working wife feels more useful (reverse coded), (d) employment of wives leads to juvenile delinquency, (e) inflation necessitates employment of both parents (reverse coded), (f) traditional husband/wife roles are best, (g) men should share household (reverse coded), and (h) women are happier in traditional roles $^{2}$. Items were scored on a four-point scale of agreeable resulting in a possible score of 8 to 32 with higher scores representing more traditional gender role attitudes.

Relationship Investment. Respondents who were married were coded 1 and those who were living together, but not married, were coded 0 . Because of the construction of the relationship status question, duration of relationship was not used in the analysis. Given the youth of the sample, it is reasonable to assume that all couples have a relatively short duration. The number of children in the household was also used to capture relationship investment.

Control Variables. Four demographic variables were identified as important contributors to relationship quality in the literature and are therefore included in the regression analyses.

\footnotetext{
${ }^{1}$ For ease of interpretation, the argument variables were entered as continuous variables in the regression model. Results were not significantly different when the variable was entered as a categorical variable.

${ }^{2}$ Removable of one item (a working wife feels more useful) increased the alpha to .71 . Regression results were not significantly different with the reduced scale, so all items were retained to be consistent with other studies using the NLSY family attitude scale.
} 
These include gender, which was measured by coding men 1 and women 0 , race, age, and education. Race is limited to the three categories of (a) Hispanic, (b) Black, and (c) nonHispanic, non-Black in the NLSY data. Age and years of education were input as continuous variables in the regression analyses. Income and employment status are two other known variables to possibly influence relationship quality among couples. These data variables were not included in the regression due to their high correlation with educational status. Since difference in partner income was included in the regression analysis, education was retained as a control variable. However, the results did not vary when income was used instead of education. When both variables were included as control variables in the regression, both variables lost their statistical significance in the women-only model.

\section{Data Analysis}

This study utilized three separate logistic regressions predicting respondents with the highest reported level of relationship quality. While an ordered logit model would also be an appropriate analysis for this study, the goal was to predict respondents with the highest possible level of relationship quality. As shown in the results, a large percentage of the sample reported the highest level of relationship satisfaction making them an interesting group to evaluate compared to all others in the sample. The first model included all respondents. The second model was restricted to males and the third model was restricted to females to more clearly illustrate how relationship quality may differ based on sex.

\section{Results}

\section{Descriptive Statistics}

The sample reported a very high relationship quality $(\mathrm{M}=11.40$, Range $=3-12)$. Consequently, the regression analysis sought to determine the characteristics of the highly 
satisfied respondents who were subsequently coded 1 (those who scored the maximum points on the relationship quality assessment). Respondents not scoring the maximum relationship quality score were coded 0 for the regression; $65 \%$ of men and $69 \%$ of women reported the highest level of relationship quality.

Sixty-six percent of men reported that they did about as many chores as their partner ( $21 \%$ of men reported to do more and $13 \%$ reported to do less). Conversely, only $33 \%$ of women reported that they did about as many chores as their partner. Nearly $64 \%$ of women reported that they actually did more chores than their partner, while $3 \%$ reported that they did less chores. There were slightly more frequent reports of arguments about money ( 2.35 for men; 2.37 for women) than affection (2.15 for men; 1.97 for women).

Men in the sample earned, on average, $\$ 6,868$ more than their partner and women earned, on average, \$15,206 less than their partner. Men worked, on average, 2.13 more hours per week than their partner while women worked, on average, 8.14 less hours per week than their partner. Male and female respondents reported a similar level of traditional gender role attitudes, on average, (15.87 versus 15.75 , respectively) while a slight preference toward less traditional attitudes.

The sample was slightly biased toward women (60\% of sample) and those with children (mean number of children of 1.9). Approximately $2 / 3$ of men and women were married versus living with a partner, but not married.

The sample consisted of $43 \%$ non-Black, non-Hispanic men and $49 \%$ non-Black, nonHispanic women, 31\% Black men and 24\% Black women, and 26\% Hispanic men and 28\% Hispanic women. The average age of men was 27.61 and 26.66 for women. Men had, on average 12.40 years of education and women had, on average, 13.06 years of education with a range of 5 
to 19 years for both genders. Table 1 shows the mean values for the variables used in the regression analysis.

\section{[Insert Table 1 about here]}

\section{Regression Analysis}

The logistic regression results indicate that the concept of resource allocation is important for both genders. In fact, it was the only concept that generated statistical significance in the full model. Respondents who reported arguing about affection and money were associated with low reported relationship quality $(\mathrm{b}=-.37, p<.001$ for both variables). The model fit was decent with a likelihood ratio of $48.30(p<.001)$ and $67.5 \%$ likelihood of accurately predicting the outcome variable.

Reporting a high frequency of arguments about money was negatively associated with men's relationship quality $(\mathrm{b}=-.45, p<.01)$. Being married (versus living with a partner) was also marginally and positively associated with men's relationship quality $(b=.71, p<.10)$. The men only model had a percent concordant of $66.6 \%$ and a likelihood ratio of 19.85 that was only marginally significant at the .10 level. It is possible that the variables used are not good measures of men's relationship quality. According to Amato and Rogers (1997), men often do not report or are unaware of the reason for divorce. This could possibly explain the lack of significance in predicting relationship quality of men.

A high frequency of arguments about affection $(b=-.47, p<.001)$ and money $(b=-.35$, $p<.05)$ were negatively associated with women's relationship quality. Further, women who perceived that they were doing more than their fair share of household chores were more likely to report a lower level of relationship quality $(b=-.63, p<.05)$ within the concept of resource allocation. Control variables that showed statistical significance in the women only model 
included years of education being negatively related to relationship quality $(\mathrm{b}=-.15, p<.05)$ and being Hispanic versus non-Black, non-Hispanic being negatively related to relationship quality, although only marginally significant $(\mathrm{b}=-.57, p<.10)$. The women only model had a high percent concordant of $70.9 \%$ and a likelihood ratio of $41.79(p<.001)$ indicating a good model fit. The models may not fully account for the endogeneity of relationship quality. In particular, our data does not allow for the measurement of fertility decisions, which would account for the presence or absence of children.

\section{[Insert Table 2 about here]}

\section{Discussion}

Economic variables alone cannot explain the variations that are reported in relationship quality. By incorporating both economic and gender theory, this study provides a more accurate description of the relationships between resource allocation, assertive mating, relationship investment and relationship quality. The primary purpose of this study was to determine how the perception of household chores is related to relationship quality. We accomplished this by examining the concepts associated with relationship quality among a young cohort of individuals. Feeling that household work is unfairly divided may, in fact, reduce perceptions of relationship quality, at least among women. When females felt that they were doing more than half of the household chores, their relationship quality fell. This finding may indicate that perception is more important in relationship quality than actual behavior, which would be consistent with previous research that has found that one's perception of partner spending behavior is more influential in determining relationship quality than actual partner spending (Britt et al. 2008). 
Also important in predicting relationship quality at the aggregate was arguments about money and affection. Although it is unknown what couples are specifically arguing about, the conceptual model predicts that it is likely in regards to how money is distributed within the household. What is interesting to note is that differences in income among partners was not a statistically significant predictor of relationship quality.

The inclusion of gender allowed us to identify possible gender differences that exist among factors that impact relationship quality. For example, perceived fairness of household chore distribution was only statistically predictive of relationship quality among the women in this study. Relationship quality was predicted to be at the lower level when women felt that they were doing more than half of the household chores. The same effect was not found for men.

It is interesting to note that the control variables of race, age, and educational status were not largely predictive of relationship quality as might be expected from the literature. It is unknown why these variables did not produce statistical significance in our study, although we hypothesize it that it is related to the features of our young sample. The sample range was relatively narrow with a span of just 20 years (respondents were ages 17 to 37 ). It is possible that this younger generation is not as influenced by racial and educational effects as was the case with previous generations.

\section{Limitations and Implications}

This study contributes to the literature in an important way by bringing greater awareness to work that began over two decades ago when sociologist Hochschild (1989) identified the gender difference in the division of household labor among dual earner couples. The gender difference is such that working women find themselves coming home from a full day at work only to put in a second shift of domestic work. Although the proportion of time spent doing 
housework by men has increased over the decades women continue to devote more time to these household tasks (Ciscel et al. 2000). This study goes beyond men and women's division of household labor and identifies the gender differences in how the perception of division of labor impacts couples' relationship quality. While these results are a unique contribution to the literature, it is important to note that the data is limited to participants who were between the ages of 17 and $37(M=27)$ and are married or living with a partner, thus limiting the generalizability of our finding to similar cohorts. Younger generations of adults are thought to have more non-traditional gender role attitudes, and be more egalitarian in their divisions of labor than previous generations (Brewster and Padovic 2000). Therefore, by evaluating a younger population we are adding to the literature by identify factors that influence the relationship quality of younger generations.

The results for men and women were not identical indicating that a gender effect may exist. Perhaps this gender difference arises because dual earner women and men have different expectations of how much their partner will contribute to the division of household labor. Given the nature of traditional gender roles in our society, and the fact that a greater percentage of working women also perform the majority of the housework, women who expect more egalitarian division are more likely to have their expectations unmet. This can add to women's role strain and possibly lead to a decrease in satisfaction with her relationship. Perhaps this is why unmarried men expect there to be equality in the division of household labor and childcare, while their female counterparts hold lower expectations of such equality (Askari et al. 2010).

When women started working in the paid labor force, it may have been seen as an opportunity rather than a necessity and they may have felt as though they owed it to their families (partner and children) to maintain their home in addition to their paid jobs. Perhaps the 
term "labor of love" has been derived from the very nature of women's role in society to care for their home and family. However, as women have taken on more demanding roles outside the home, either by choice or necessity, there is a greater sense of unfairness arising in the division of household labor. If women are to continue contributing to the labor workforce and maintaining a happy marriage there needs to be a culture shift that recognizes the inequality of work at home and an overall reallocation of role expectations. The most productive culture shift would be a greater emphasis and availability on work-family policy. Although the Family Medical Leave Act (FMLA) of 1993 was intended to aid families in balancing the demands of work and family, it contains significant limitations. This FMLA, which allows eligible workers 12 weeks of job-protected leave during a 12-month period to care for newborns or adopted children and also for serious medical problems experienced by relatives or themselves, is for unpaid leave, applies only to companies with more than 50 employees, and the applicant must have worked for their employer for at least 1,250 hours during the past 12 months. In addition, position reinstatement is not guaranteed. Employees on FMLA are forced to use any sick leave or vacation time to receive pay, which usually does not cover the full 12 weeks. More importantly, when it comes to taking leave studies evaluating new mothers (Klerman and Leibowitz 1999) or families with young children (Hen and Waldfoel 2003) have found little evidence that such laws increase the amount of leave taken. Perhaps a more long-term solution would be more beneficial to younger working families trying to strike a balance between work and family.

The availability of other work family policies such as parental leave, flex-time, and employee provided childcare acknowledge family responsibilities of employers (Estes et al. 2007). These work-family policies have been positively associated with men's share of female- 
typed tasks (Estes et al. 2007). If work-family policy can improve the equality perceived in relationships and, in turn, has a positive effect on relationship quality there needs to be greater attention placed on the availability of such policies. Future research on dual-earner couples must acknowledge the gender differences that exist in how their perceptions of household labor can influence their relationship quality. It is only when these gender differences have been acknowledged that practitioners working with dual-earner couples can more adequately support the concerns among these couples. Once practitioners understand that perceptions of household task can affect men and women's relationship quality differently they will be able to better facilitate conversations among couples on this important issue. It is important that clients are made aware of this gender difference in hopes that awareness can lead to positive changes for the couple. In particular, male clients with female partners should be alerted to the reality that it may not be just about what they do but what is perceived as being done. 


\section{References}

Askari, S. F., Liss, M., Erchull, M. J., Staebell, S. E., \& Axelson, S. J. (2010). Men want equality, but women don't expect it: Young adults' expectations for participation in household and child care chores. Psychology of Women Quarterly, 34(2), 243-252. doi: $10.1111 / \mathrm{j} .1471-6402.2010 .01565 . \mathrm{x}$

Amato, P., \& Booth, A. (1995). Changes in gender role attitudes and perceived marital quality. American Psychological Review, 60, 58-66. doi:10.2307/2096345

Amato, P. R., \& Rogers, S. J. (1997). A longitudinal study of marital problems and subsequent divorce. Journal of Marriage and the Family, 59(3), 612-624. http://dx.doi.org/10.2307/353949

Baxter, J., Hewitt, B., \& Haynes, M. (2008). Life course transitions and housework: Marriage, parenthood, and time on housework. Journal of Marriage and Family, 70, 259-272. doi: 10.1111/j.1741-3737.2008.00479.x

Becker, G. S. (1976). The economic approach to human behavior. Chicago: The University of Chicago Press.

Biehle, S. N., \& Mickelson, K. D. (2012). First-time parents' expectations about the division of childcare and play. Journal of Family Psychology, 26(1), 36-45. doi: 10.1037/a0026608

Bittman, M., England, P., Folbre, N., Sayer, L., Matheson, G. (2003). When does gender trump money? Bargaining and time in household work. American Journal of Sociology, 109(1), 186-214. doi: 10.1177/0950017007087416

Blair, S. L., \& Johnson, M. P. (1992). Wives' perceptions of the fairness of the division of household labor: The intersection of housework and ideology. Journal of Marriage and the Family, 54, 570-581. doi: 10.1177/1350506803010002004 
Bradbury, T. N., Fincham, F. D., \& Beach, S. R. H. (2000). Research on the nature and determinants of marital satisfaction: A decade in review. Journal of Marriage and Family, 62, 964-980. doi:10.1111/j.1741-3737.2000.00964.x

Brewster, K., \& Padovic, I. (2000). Changer in gender ideology, 1977-1996: The contributions of intracohort changes and population turnover. Journal of Marriage and Family, 62, 477487. doi:10.1111/j.1741-3737.2000.00477.x

Brines, J., \& Joyner, K. (1999). The ties that bind: Principles of cohesion in cohabitation and marriage. American Sociological Review, 64, 333-355. Retrieved from http://www.jstor.org/stable/2657490

Britt, S., Grable, J. E., Nelson Goff, B. S., \& White, M. (2008). The influence of perceived spending behaviors on relationship satisfaction. Financial Counseling and Planning, 19(1), 31-43.

Britt, S. L., Huston, S. J., \& Durband, D. B. (2010). The determinants of money arguments between spouses. Journal of Financial Therapy, 1(1), 41-59. Retrieved from http://dx.doi.org/10.4148/jft.v3i1.1605

Brooks, C., \& Bolzendahl, C. (2004). The transformation of US gender role attitudes: cohort replacement, social-structural change, and ideological learning. Social Science Research, 33, 106-133. doi:10.1016/S0049-089X(03)00041-3

Ciscel, D. H., Sharp, D. C., \& Heath, J. A. (2000). Family work trends and practices: 1971 to 1991. Journal of Family and Economic Issues, 21(1), 23-36. doi:

10.1023/A:1009475313602 
Coltrane, S. (2000). Research on household labor: Modeling and measuring the social embeddedness of routine family work. Journal of Marriage and Family, 62, 1208-1233. doi:10.1111/j.1741-3737.2000.01208.x

Coltrane, S., \& Shih, K. Y. (2010). Gender and the division of labor. In J. C. Chrisler \& D. R. McCreary (Eds.), Handbook of gender research in psychology (pp. 401-422). New York, NY: Springer. doi: 10.1007/978-1-4419-1467-5-17

Cowan, C. P., \& Cowan, P. A. (2000). When partners become parents: The big life change for couples. New York, NY: Basic Books.

Crohan, S. E. (1996). Marital quality and conflict across the transition to parenthood in African American and White couples. Journal of Marriage \& Family, 58, 933-944. Retrieved from http://www.jstor.org/stable/35398

Demo, D. H., \& Acock, A. C. (1993). Family diversity and the division of domestic labor: How much have things really changed? Family Relations, 42, 323-331. Retrieved from http://www.jstor.org/stable/585562 .

Dew, J. P. (2009, November). Financial issues as predictors of divorce. Paper presented at the annual conference of the National Council on Family Relations, San Francisco, CA.

Dew, J., Britt, S. L., \& Huston, S. J. (2012). Examining the relationship between financial issues and divorce. Family Relations, 61, 615-628. doi:10.1111/j.1741-3729.2012.00715.x

Engfer, M. (1988). The interrelatedness of marriage and the mother-child relationship. In R. Hinde \& J. Stevenson-Hinde (Eds.), Relationship within families: Mutual influences (pp. 104-118). Oxford, UK: Oxford University Press. 
Estes, S. B., Noonan, M. C., \& Maume, D. J. (2007). Is work-family policy use related to the gendered division of housework? Journal of Family and Economic Issues, 28, 527-545. doi: $10.1007 /$ s10834-007-9075-6

Ferree, M. M. (1990). Beyond separate spheres: Feminism and family research. Journal of Marriage and Family, 52(4), 866-884. Retrieved from http://www.jstor.org/stable/35330

Fuwa, M., \& Cohen, P. N. (2007). Housework and social policy. Social Science Research, 36, 512-530. doi:10.1016/j.ssresearch.2006.04.005

Greenstein, T. N. (2000). Economic dependence, gender, and the division of labor in the home: A replication and extension. Journal of Marriage and Family, 62(2), 322-335. doi: 10.1111/j.1741-3737.2000.00322.x

Gershuny, J., \& Sullivan, O. (2003). Time use, gender, and public policy regimes. Social Politics, 10, 205-227.

Hen, W., \& Waldfogel, W. (2003). Parental leave: The impact of recent legislation on parent's leave taking. Demography, 40(2), 191-200.

Hochschild, A. (1989). The Second Shift. New York, NY: Viking.

Klerman, J., \& Leibowitz, A. (1999). Job continuity among new mothers. Demography, 36(2), $145-155$.

Kluwer, E. S., \& Mikula, G. (2002). Gender-related inequalities in the division of labor in close relationships: A social psychological perspective. European Review of Social Psychology, 13, 185 - 216. doi:10.1080/10463280240000064

Kroska, A. (2003). Investigating gender differences in the meaning of household chores and child care. Journal of Marriage and Family, 65, 456-473. doi:10.1111/j.17413737.2003.00456.x 
Lawrence, E., Rothman, A. D., Cobb, R. J., Rothman, M. T., \& Bradbury, T. N. (2008). Marital satisfaction across the transition to parenthood. Journal of Family Psychology, 22, 41-50. doi: $10.1037 / 0893-3200.22 .1 .41$.

Lincoln, A. E. (2008). Gender, productivity, and the marital wage premium. Journal of Marriage and Family, 70, 806-814. doi:10.1111/j.1741-3737.2008.00523.x

Lorensen, M., Wilson, M. E., \& White, M. A. (2004) Norwegian families: Transition to parenthood. Health Care for Women International, 25, 334-348. doi: $10.1080 / 07399330490278394$

Lu, L. (2006). The transition to parenthood: Stress, resources, and gender differences in a Chinese society. Journal of Community Psychology, 34, 471-488. doi:10.1002/jcop. 20110

Moss, P., Bolland, G., Foxman, R., \& Owen, C. (1986). Marital relations during the transition to parenthood. Journal of Reproduction and Infant Psychology, 4, 57 - 67.

Nock, S. L. (1995). A comparison of marriage and cohabiting relationships. Journal of Family Issues, 16, 53-76. doi: 10.1177/019251395016001004

Orrange, R. M. (2002). Aspiring law and business professionals' orientations to work and family life. Journal of Family Issues, 23, 287-317. doi: 10.1177/0192513X02023002006

Rollins, B. C., \& Feldman, H. (1970). Marital satisfaction over the family life cycle. Journal of Marriage and the Family, 32, 20 - 27.

Salmela-Aro K., Aunola K., Saisto T., Halmesmaki E., \& Nurmi J. (2006). Couples share similar changes in depressive symptoms and marital satisfaction anticipating the birth of a child. Journal of Social and Personal Relationships, 23, 781-803. doi:

$10.1177 / 0265407506068263$ 
Shapiro, A. F., Gottman, J. M., \& Carrére, S. (2000). The baby and the marriage: Identifying factors that buffer against decline in marital satisfaction after the first baby arrives. Journal of Family Psychology, 14, 59-70.

Szuchman, P., \& Anderson, J. (2011). Spousonomics: Using economics to master love, marriage, and dirty dishes. New York, NY: Random House.

Thompson, L., \& Walker, A. J. (1989). Gender in families: Women and men in marriage, work and parenthood. Journal of Marriage and the Family, 51, 845-871. Retrieved from http://www.jstor.org/stable/353201

Tichenor, V. J. (1999). Status and income as gendered resources: The case of marital power. Journal of Marriage and Family, 61, 638-650. Retrieved from http://www.jstor.org/stable/353566

U.S. Census Bureau (2011). Married-Couple Households by Labor Force Status of Spouse: 1990 to 2009. Labor Force, Employment, and Earnings U.S. Census Bureau, Statistical Abstract of the United States. Retrieved November 10, 2012 from http://www.census.gov/compendia/statab/2011/tables/11s0600.pdf

Weagley, R. O., Chan, M., \& Yan, J. (2007). Married couples' time allocation decisions and marital stability. Journal of Family and Economic Issues, 28, 507-525. doi: $10.1007 / \mathrm{s} 10834-007-9070-\mathrm{y}$ 
Table 1. Descriptive Statistics $(N=554)$

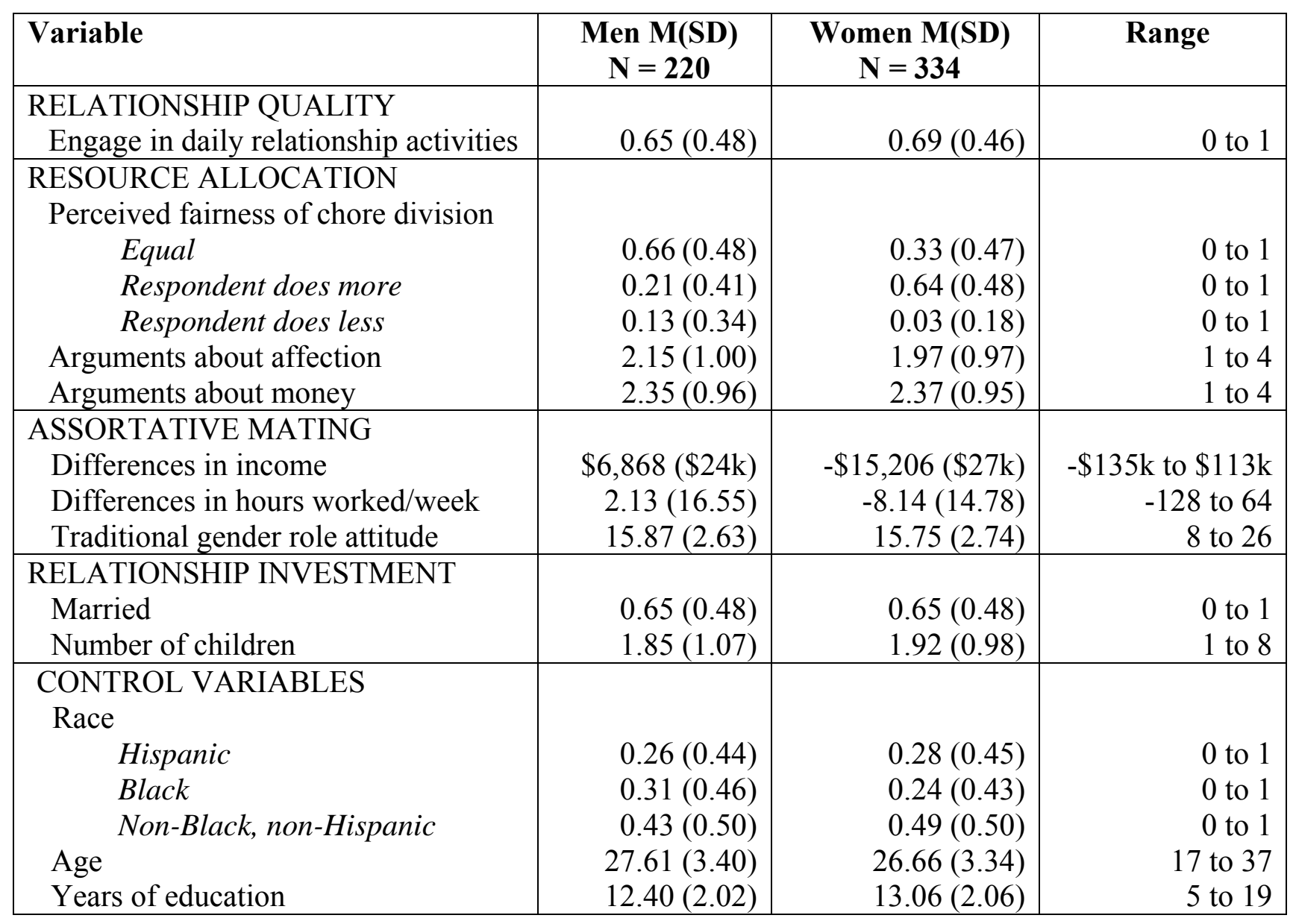


Table 2. Regression Results Predicting High Relationship Quality

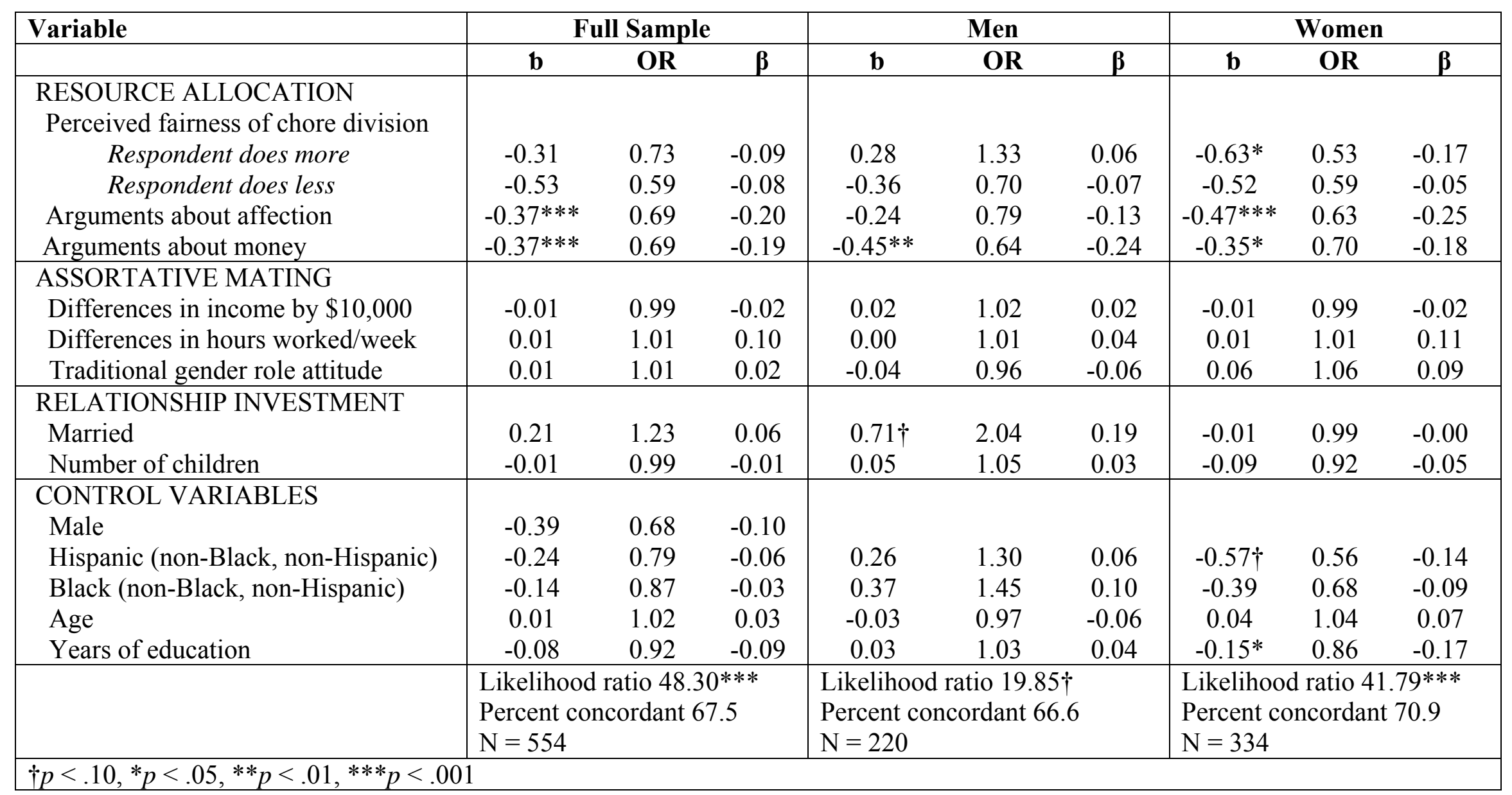

